Bond University

Research Repository

\title{
Drinking motives, drinking restraint and drinking behaviour among young adults
}

Lyvers, Michael; Hasking, Penelope; Hani, Riana; Rhodes, Madolyn; Trew, Emily

Published in:

Addictive Behaviors

DOI:

10.1016/j.addbeh.2009.09.011

\section{Licence:}

CC BY-NC-ND

Link to output in Bond University research repository.

Recommended citation(APA):

Lyvers, M., Hasking, P., Hani, R., Rhodes, M., \& Trew, E. (2010). Drinking motives, drinking restraint and drinking behaviour among young adults. Addictive Behaviors, 35(2), 116-122.

https://doi.org/10.1016/j.addbeh.2009.09.011

\section{General rights}

Copyright and moral rights for the publications made accessible in the public portal are retained by the authors and/or other copyright owners and it is a condition of accessing publications that users recognise and abide by the legal requirements associated with these rights.

For more information, or if you believe that this document breaches copyright, please contact the Bond University research repository coordinator. 
Drinking Motives, Drinking Restraint and Drinking Behavior among Young Adults 


\begin{abstract}
Motives to drink alcohol are widely thought to be the proximal cognitive factors involved in the decision to consume alcohol beverages. However, the ability to restrain drinking may be a more proximal predictor of drinking behavior. The current study examined the relationships between drinking motives, drinking restraint, and both alcohol consumption and alcoholrelated problems in young adults aged 17-34 years. A sample of 221 students and nonstudents completed self-report measures assessing drinking behavior, motives for drinking and drinking restraint. Multiple regression analyses revealed that coping, enhancement and social motives were related to alcohol consumption and alcohol-related problems, while cognitive/emotional preoccupation with drinking was related to all criterion variables. The relationship between coping motives and drinking behavior was mediated by preoccupation with drinking. The results are discussed in light of the roles of drinking motives and drinking restraint in risky drinking among young people. Implications for prevention and early intervention are also discussed.
\end{abstract}

Keywords: drinking motives; drinking restraint; drinking behavior 
Excessive alcohol use among young adults has been associated with adverse outcomes such as fatal and non-fatal injuries, blackouts, suicide attempts, unintended pregnancy, sexually transmitted diseases, academic failure, and violence (Hingson, Heeren, Zakocs, Kopstein, \& Wechsler, 2002; Perkins, 2002). In Australia, young people between the ages of 20 and 29 years old maintain the highest level of alcohol consumption and are at highest risk of alcohol-related harm (AIHW, 2008; Kuntsche, Knibbe, Gmel \& Engels, 2005). In addition to short term harm, these young people may also be at risk of long term harm such as impaired brain, liver and other organ functioning (Cox, Hosier, Crossley, Kendell \& Roberts, 2006). Despite such consequences, a large majority of university students - the majority of whom are in this high risk age bracket - drink alcohol, and over half can be classified as moderate or heavy drinkers (O’Hara, 1990; Wechsler \& Isaac, 1992). To effectively control excessive drinking and drinking problems in Australia's younger adult population, it is necessary to understand the factors associated with drinking behavior. By knowing the correlates of alcohol consumption amongst this demographic, we can attempt to intervene with a psychological evidence-based approach. The aim of the current study was to examine the relationships between drinking motives, drinking restraint, alcohol consumption, and alcohol-related problems among young adults including students and non-students.

\section{Drinking motives}

According to motivational models of alcohol use, although numerous factors are related to drinking, motivations to drink alcohol constitute the final common pathway to its use, whereby an individual makes the decision to drink based on anticipated positive and/or negative reinforcement (Cooper, 1994; Cooper, Frone, Russell, \& Mudar, 1995; Cox \& Klinger, 1988). Although people may consume alcohol for varied reasons, four primary motivations identified by Cooper (1994) have been the primary focus of empirical investigation. 
Social motives to drink alcohol represent anticipated positive reinforcement in the form of social rewards (Cooper, 1994; Cooper, Russell, Skinner \& Windle, 1992; Cox, et al., 2006; MacLean \& Lecci, 2000; Stewart, Zeitlin \& Somoluk, 1996). Not surprisingly, social motives are commonly endorsed by drinkers in a social setting. Social motives tend not to be significantly related to heavy drinking or alcohol problems, but rather are often associated with light, infrequent and non-problematic alcohol use (Cooper, 1994; Read, Wood, Kahler, Maddock, \& Palfai, 2003). Likewise conformity motives, or drinking to avoid social disapproval, are often reported by adolescents and young adults, and are likely to weaken with maturity (Cooper, 1994).

Conversely, drinking as a result of enhancement or coping motives has often been associated with heavy alcohol use and alcohol-related problems (Cooper, 1994; Grant, Stewart, O’ Connor, Blackwell \& Conrad, 2007; McNally, Palfai, Levine \& Moore, 2003). Coping motives represent anticipated negative reinforcement by regulation or elimination of negative emotions. In previous studies, coping motives have been related to heavy problematic drinking (Cooper et al., 1992; MacLean \& Lecci, 2000; McNally et al., 2003; Stewart et al., 1996) and have been both indirectly (thorough the level of alcohol consumed) and directly (independent of the level of alcohol consumed) related to alcohol problems (Cooper, 1994). Enhancement motives represent anticipated positive reinforcement in the form of enhanced positive mood or well-being. Drinking for enhancement has previously predicted heavy alcohol use, especially in situations that encourage heavy drinking (Cooper, 1994).

While these relationships are relatively consistent in the research literature, mixed results have also been reported. In 1999, Bradizza, Reifman and Barnes reported that social motives were more strongly related to alcohol misuse than coping motives in a sample of adolescents. More recently, coping motives were not observed to predict alcohol consumption among 
university students, but predicted alcohol-related problems in cross-sectional analyses (Read et al., 2003). One explanation for these discrepant findings is that additional variables are related to both drinking motives and drinking behavior. Specifically, although motives are generally thought to be proximal predictors of drinking behavior, in some situations a person may be motivated to drink but resist consuming alcohol. Conversely, an individual may not express a conscious motivation to drink, but struggles in their ability to resist drinking. Thus, although motives are clearly related to drinking behavior, drinking restraint may be a more proximal predictor of alcohol consumption.

\section{Drinking restraint}

The inability to restrain drinking has been studied extensively with clinical and nonclinical samples, university students and adult populations (Bensley, Kuna \& Steele, 1990; Connor, Gudgeon, Young, \& Saunders, 2004; Connors, Collins, Dermen \& Koutsky, 1998; Cox, Gutzler, Denzler, Melfsen, Florin \& Klinger, 2001; MacKillop, Lisman \& Weinstein, 2006; Muraven, Collins \& Nienhaus, 2002; Stewart \& Chambers, 2000). Drinking restraint has been linked to binge drinking, episodic excessive drinking (Collins, George \& Lapp, 1989), and alcohol dependence (MacKillop et al., 2006). However, multiple factors determine whether an individual is able to restrain drinking.

In 1989 Collins et al. defined five dimensions of drinking restraint, which differentially predict level of alcohol risk. These dimensions include difficulty controlling intake, negative affect as a reason for drinking, thoughts about drinking, attempts to limit drinking, and plans to reduce drinking or worry about controlling drinking. From these five factors, the Temptation and Restraint Inventory (TRI) was developed assessing two aspects of restraint that represent competing tendencies and thus, different antecedents and consequences of drinking alcohol (Collins et al., 1989). 
The first factor, Cognitive and Emotional Preoccupation (CEP), has been strongly linked to an increased intake of alcohol and predicts high risk of alcohol problems and alcohol dependence (MacKillop et al., 2006). The second factor, Cognitive and Behavioral Control (CBC), represents attempts to control alcohol use (MacKillop et al., 2006). High CEP scores are thought to be related to increased drinking, whereas high $\mathrm{CBC}$ scores are thought to relate to less drinking, relationships which have consistently been observed in non-clinical samples (Collins, Koutsky, Morsheimer, \& MacLean, 2001; Collins \& Lapp, 1992; Stewart \& Chambers, 2000; Williams \& Ricciardelli, 1999). However CBC has been related to increased consumption, but not alcohol-related problems, in high risk and dependent drinkers (Connor et al., 2004; MacKillop et al., 2006). Consequently, drinking restraint is believed to have greater utility in understanding drinking behavior and alcohol-related problems in nondependent drinkers (Connor et al., 2004).

The relationship between drinking motives and restraint

Although related, drinking motives and drinking restraint represent two distinct cognitive pathways to drinking. Consistent with the notion that restraint is a more proximal predictor of drinking behavior, Stewart and Chambers (2000) proposed that drinking motives would predict alcohol consumption and risk of alcohol-related problems through their relationship with drinking restraint. As those who drink primarily for enhancement motives are generally at less risk of alcohol-related problems than those who drink for coping motives, Stewart and Chambers (2000) hypothesised that those with coping and enhancement motives would be highly preoccupied with thoughts about drinking, but those with coping motives would have less control over their drinking behavior than those with enhancement motives. Thus they proposed that coping and enhancement motives would predict higher CEP scores whereas enhancement but not coping motives would predict higher CBC scores. Results of their study of 97 university students supported the proposition that both coping and enhancement 
motives predicted higher CEP scores. However, enhancement motives failed to predict CBC scores, while coping motives were positively related to $\mathrm{CBC}$ scores. Further, social motives were not related to either restraint factor. Stewart and Chambers (2000) explained this counter-intuitive finding by suggesting that those reporting coping motives were more concerned with limiting their drinking, and may thus be at reduced risk of alcohol problems relative to those reporting enhancement motives.

In partial support for this premise, Martens, Ferrier, and Cimini (2007) reported that the relationships between social and enhancement drinking motives and both alcohol use and alcohol-related problems were partially mediated by protective behavioral strategies used to limit alcohol use in a sample of undergraduate students. Individuals with stronger motives reported fewer protective behavioral strategies, which in turn predicted greater alcohol use and more alcohol-related problems.

The current study

The current study aimed to replicate and extend the work of Stewart and Chambers (2000) by examining the relationships between all four coping motives, drinking restraint and drinking behavior. Further, given previous literature cited above which suggests motives and restraint may be differentially related to alcohol consumption and alcohol-related problems, we aimed to examine both outcome variables. Finally, given the previous over-reliance on university populations, we aimed to expand our recruitment beyond university students in order to extend the external validity of the findings.

Based on previous work cited above, we hypothesised that coping and enhancement motives would be more strongly related to drinking behavior than social and conformity motives. Secondly we hypothesised that drinking restraint would be related to alcohol consumption and alcohol-related problems. Specifically, we proposed that CEP would be positively related to drinking behavior, whereas $\mathrm{CBC}$ would be negatively related to drinking 
and alcohol-related problems. Finally, we proposed that the relationship between drinking motives and drinking behavior would be mediated by drinking restraint. Based on the previous findings of Stewart and Chambers (2000) and Martens et al. (2007), we expected the relationship between social, enhancement and coping motives and drinking behavior to be mediated by $\mathrm{CBC}$, such that stronger motives predict higher $\mathrm{CBC}$ scores which in turn are related to lowered drinking. Further we anticipated that both coping and enhancement motives would be related to CEP scores which would in turn be related to greater alcohol consumption and more alcohol-related problems.

\section{Method}

\section{Participants}

The sample consisted of 221 young adults from the Gold Coast region of Australia. Of these, 122 were recruited from universities and 99 were recruited from the broader community. Of those recruited from the community, 13 were currently studying, providing a final sample of 135 students and 86 non-students. Of the total sample, there were 99 females, 89 males and 33 who did not report gender. Ages ranged between 17-34 years with a mean age of 22.01 years $(\mathrm{sd}=3.40)$. The majority of the sample was currently in either part-time or full-time employment (65.3\% of student sample; $86.9 \%$ of community sample). Of the overall sample, $97.7 \%$ consumed alcohol, with $96.4 \%$ of the sample reporting that they consumed their first drink while underage (18 years in Australia). Of the sample $76.9 \%$ said they consumed their first alcoholic drink under the age of 16 , and $25.8 \%$ reported consuming their first drink before the age of 13.

\section{Measures}

Drinking Motives Questionnaire-Revised (DMQ-R). The DMQ-R has 20 self-report items designed to determine the motives behind drinking behaviour (Cooper, 1994). Constructed in line with the motivational model of alcohol use, the DMQ-R was validated 
through confirmatory factor analysis and normed on adolescents 13 to 19 years old (Kuntsche et al., 2005). The DMQ-R measures four motives: social (e.g., 'how often do you drink to celebrate a special occasion with friends?'), conformity (e.g., 'how often do you drink to be liked?'), enhancement (e.g., 'how often do you drink because you like the feeling?'), and coping (e.g., 'how often do you drink to forget your worries?'). Each factor is represented by five items, to which respondents rate the relative frequency at which they consume alcohol for that reason on a 5-point Likert scale $(1=$ almost never/never, 5 =almost always/always $)$. High factor scores reflect higher factor endorsement independent of alcohol consumption frequency (Stewart et al., 2002). In the present study conformity motives were not assessed as these were found to be unrelated to drinking in a previous study of young adults (Lyvers et al., 2010).

The Drinking Motives Questionnaire (DMQ). Drinking Motives were measured using the DMQ, a 20-item scale that was developed by Cooper (1994) and defined by four factors: Social, Coping, Enhancement and Conformity motives for drinking alcohol. Social motives reflect drinking to enhance positive social rewards (e.g., "Because it helps you enjoy a party"); Coping motives reflect drinking to reduce or regulate negative emotions (e.g., "Because it helps you when you feel depressed or nervous"); Enhancement motives reflect drinking for enhancing positive mood or well-being (e.g., "Because it gives you a pleasant feeling”); and Conformity motives reflect drinking to avoid social censure or rejection (e.g., "So that others won't kid you about not drinking") (Cooper, 1994). All items were measured on a 5-point Likert scale ( $1=$ almost never/never; 5 = almost always/always $)$, with higher scores indicating stronger motives. Internal consistency of the scale has been established with a mean reliability coefficient of 0.87 within a range of 0.81-0.92 (MacLean \& Lecci, 2000). Test-retest reliability was also established and found to be invariant across gender, race and 
age (Cooper et al., 1992; Cooper, 2004), while reliability of the factor structure has been confirmed (Grant et al., 2007; MacLean \& Lecci, 2000).

The Temptation and Restraint Inventory (TRI). Drinking Restraint was measured using the TRI (Collins \& Lapp, 1992), a 15-item self-report instrument measuring cognitive, emotional and behavioral traits related to restraint and control over drinking. Collins and Lapp (1992) developed this scale to measure drinking restraint as "the preoccupation of controlling alcohol consumption." Individuals indicated how often they think about or try to control their drinking, rating statements on a 9-point scale $(1=$ never/not at all to $9=$ always/extremely). The items summate to produce to two subscales: Cognitive and Emotional Preoccupation (CEP), which reflects the temptation to drink, and Cognitive and Behavioral Control (CBC), which measures the control/restriction of alcohol intake (Collins \& Lapp, 1992). Reliability (alphas .76 to .91), construct validity and predictive validity have been established in adolescent, university, clinical and non-clinical adult samples (Collins \& Lapp, 1992; MacKillop et al., 2006).

Alcohol Use Disorders Identification Test (AUDIT). The AUDIT (Babor \& HigginsBiddle, 2001) is a 10-item scale designed to identify alcohol risk and potential problems associated with drinking. In addition to a single AUDIT score reflecting alcohol-risk, the AUDIT can also be scored to reflect three different indices of drinking behavior: alcohol consumption, alcohol-related problems, and alcohol-dependence. For the purposes of this study, both the total AUDIT score and the three subscales were utilised. The AUDIT has demonstrated a high degree of internal consistency yielding a comparable median reliability coefficient of 0.83 , with a range of 0.75 to 0.97 (Reinert \& Allen, 2007). The AUDIT has also shown adequate test-retest reliability with non-clinical as well as alcohol-dependent samples (Reinert \& Allen, 2007). Criterion validity has also been established in the English 
language version of the AUDIT and it has consistently proven to be an adequate alcohol screen in various settings (Reinert \& Allen, 2007).

\section{Procedure}

After gaining ethical approval, participants were approached either on campus (at cafes, library and outside areas) or in a major shopping mall known to be popular with young adults. The researchers approached prospective participants who appeared to be young adults within the desired age range of 18-30 years, however the actual age range of the sample was slightly broader than this range (i.e., 17-34 years). All participants indicated that they could speak, read and write English fluently. Participants were invited to participate in the study after the aims and study requirements were explained. Those who agreed to participate were provided with an anonymous survey package, which took approximately 15 minutes to compete. In exchange for their participation, all participants were offered an entry form for the chance to win a $\$ 50$ Gift Card.

\section{Results}

Prior to conducting regression analyses, multivariate analysis of variance was conducted to examine whether participant samples differed on the variables under investigation. No differences were observed between the student and non-student samples on any measures (all $p>.05)$. Consequently the samples were combined for the main analyses. A score of 8 or above on the total AUDIT is generally considered indicative of risky drinking (Roche \& Watt, 1999). A score above 7 on the consumption scale, above 4 on the dependence scale, and any positive response on the alcohol-related problems scale is indicative of risky drinking (Babor \& Higgins-Biddle, 2001). Consistent with previous studies (O'Hara, 1990; Wechsler \& Isaac, 1992), approximately 50\% of this sample reported risky alcohol consumption (see 
Table 1). Approximately one-quarter of the sample appeared to be at risk of alcoholdependence, while more than three-quarters of the sample reported alcohol-related problems. Correlations between all variables can be seen in Table 2 . The majority of variables were positively related to each other, including $\mathrm{CBC}$ and the drinking measures.

In order to examine whether $\mathrm{CEP}$ and $\mathrm{CBC}$ mediate the relationship between drinking motives and total AUDIT score, a single hierarchical regression was performed. Gender and age were statistically controlled by entering them in the first step of the regression equation. The unique effects of drinking motives were examined in the second step, while CEP and $\mathrm{CBC}$ were entered in the final step of the regression. As seen in Table 3, men had higher AUDIT scores than women. Drinking motives significantly added to the prediction of AUDIT scores at Step 2. Specifically, coping motives, social motives and enhancement motives were all positively related to AUDIT. At Step 3, only CEP added unique variance to the regression equation. Further, although social and enhancement motives remained significant in the final step, coping motives were no longer related to AUDIT, $\beta=.03$. A Sobel test (Baron \& Kenny, 1986) confirmed that the relationship between coping motives and AUDIT was mediated by CEP, $Z=4.90, p=.000$ (see Figure 1 ).

To further examine the nature of the relationships between drinking motives, CEP, CBC and drinking behavior as assessed by the AUDIT, three additional regression analyses were conducted, one for each subscale of the AUDIT (alcohol consumption, alcohol-related problems, alcohol dependence). As seen in Table 4, differential relationships were observed according to the criterion variable. Men reported greater alcohol consumption and alcohol dependence, but not alcohol-related problems, than women. Enhancement motives were positively related to all three subscales of the AUDIT. Coping motives were positively related to alcohol dependence and alcohol related problems, but not consumption. Social motives were related to consumption and alcohol-related problems, but not dependence. Conformity 
motives were negatively related to consumption, but not related to either of the other AUDIT subscales. Although CEP was uniquely related to all three criterion variables, $\mathrm{CBC}$ was related only to alcohol-related problems, with greater $\mathrm{CBC}$ scores related to more alcoholrelated problems.

When predicting alcohol dependence, only enhancement motives remained significant at Step 3. However, although no significant relationship between coping motives and dependence was evident at this step, $\beta=-.03$, a Sobel test failed to determine that this relationship was mediated by $\mathrm{CEP}, \mathrm{Z}=.42, \mathrm{p}=.68$. Similarly, enhancement and coping motives no longer significantly predicted alcohol-related problems when CEP and CBC were entered into the equation, however Sobel tests failed to confirm that the relationships between drinking motives and alcohol-related problems were mediated by either CEP or CBC, all $\mathrm{p}>$ .05. Finally, social, conformity and enhancement motives were still significantly related to alcohol consumption when $\mathrm{CEP}$ and $\mathrm{CBC}$ were entered into the regression equation (see Table 4).

\section{Discussion}

Motives to drink alcohol are widely thought to be the proximal cognitive factors involved in the decision to drink (Cooper, 1994; Cooper, et al., 1995; Cox \& Klinger, 1988). However it has also been argued that the ability to restrain drinking may be a more proximal predictor of this behavior (Stewart \& Chambers, 2000). The current study aimed to examine the relationship between drinking motives, drinking restraint, and both alcohol consumption and alcohol-related problems among a sample of young adults, and determine whether the relationships between drinking motives and drinking behavior were mediated by drinking restraint.

Supporting our hypotheses, coping and enhancement motives were strongly related to both alcohol consumption and alcohol-related problems, while conformity motives were generally 
unrelated. Surprisingly, social motives were also significant predictors of alcohol consumption and alcohol problems. While the salience of coping and enhancement motives in predicting drinking is widely acknowledged (Cooper, 1994; Grant, et al., 2007; MacLean \& Lecci, 2000; McNally, et al, 2003; Stewart et al., 1996), social motives are generally thought to be unrelated to adverse outcomes (Cooper, 1994; Read, et al., 2003). However, social motives are related to frequency of consumption, especially in social situations (Cooper, 1994). Bradizza et al (1999) previously reported social motives to be salient predictors of drinking, particularly in mid-to-late adolescence. These results are likely to reflect the drinking culture often observed among young adults and university students (O’Hara, 1990; Wechsler \& Isaac, 1992). This culture is one that needs to be addressed if alcohol consumption and alcohol-related problems are to be reduced among young adults. Note that in the present study there were no differences in drinking motives or other relevant measures between student and non-student samples of the same age range (17-34 years).

Interestingly, in the present study the salience of drinking motives varied depending on the outcome measure examined. Coping and enhancement motives were related to alcoholrelated problems and dependence, supporting previous research which proposed that individuals who drink to cope, or use alcohol to improve positive affect, are more likely to experience alcohol-related problems (Cooper, 1994; Grant, et al., 2007; MacLean \& Lecci, 2000; McNally, et al, 2003; Stewart et al., 1996). Both enhancement and social motives were related to alcohol consumption, however coping motives were not. This pattern of results suggests that in a non-clinical sample, the decision to consume alcohol may be partly governed by anticipation of positive reinforcement (either social or internal). However when coping motives are also implicated in the decision to drink, the individual is more likely to experience adverse consequences. 
Conformity motives were not a salient predictor of the outcome variables, but were inversely related to alcohol consumption. This counter-intuitive finding may reflect response bias in the data. Perhaps respondents did not want to be seen to drink to fit in with others or as responding to peer pressure. Alternatively this relationship may reflect the success of education campaigns launched over the last 20 years, which have resulted in a change in social norms related to alcohol use. While once it may have been socially unacceptable to refuse a drink, and social drinking is still an inherent part of Australian culture (Munro, 2000), it is now considered socially inappropriate to pressure someone to drink. Such changing norms may mean that respondents were disinclined to endorse items reflecting peer pressure and conformity, yet still consumed alcohol at risky levels.

Drinking restraint was also independently related to drinking behavior. Consistent with theory and previous empirical work (Collins, et al., 2001; Collins \& Lapp, 1992; Williams \& Ricciardelli, 1999), cognitive/emotional preoccupation with drinking (CEP) was related to all criterion variables. Surprisingly however, cognitive/behavioral control (CBC) was positively related to alcohol problems. Positive relationships between $\mathrm{CBC}$ and alcohol consumption have previously been noted in high risk and clinical samples (Connor et al., 2004; MacKillop et al., 2006), but not in non-clinical samples. The high level of risky drinking evident in the current sample, and the correlational nature of this study, may explain this counter-intuitive finding. Perhaps those who are experiencing alcohol-related problems are more concerned about their drinking, and thus more likely to report cognitive and behavioral strategies to resist drinking. Similarly, those who struggle to control their drinking may be more likely to report alcohol-related problems.

Our third hypothesis was that the relationship between drinking motives and drinking behavior would be mediated by drinking restraint. Based on previous work in this area (Martens et al., 2007; Stewart \& Chambers, 2000) we expected that stronger social, 
enhancement and coping motives would predict higher CBC scores which in turn would be associated with less alcohol consumption. In addition we proposed that both coping and enhancement motives would be positively related to CEP scores which would be related to greater alcohol consumption and alcohol-related problems. Only one of these proposed relationships was observed in the current study.

Stronger coping motives were associated with CEP scores which in turn were associated with the total AUDIT score. This suggests that those who drink to cope report a greater preoccupation with drinking, which in turn is related to more drinking. Arguably, individuals who are experiencing stress or emotional problems, and have previously used alcohol to cope, will become preoccupied with drinking when faced with a similar stressful situation. This preoccupation then leads to alcohol-seeking behavior. Such a proposition is supported by cognitive theories of substance use which suggest that internal or external cues (e.g., stress) lead to beliefs and automatic thoughts (e.g., alcohol helps me cope), which in turn leads to preoccupation, craving and drug-seeking behavior (Beck, Wright, Newman, \& Liese, 1993).

Although the other proposed relationships were not observed in the current study, the salience of coping and enhancement motives in predicting alcohol problems did diminish when drinking restraint was included in the regression model. The failure to confirm mediation in the current analyses may be an artefact of overlapping variance between these constructs, as evidenced in the bivariate correlations, and an inflated standard error. A larger sample size may reveal mediated relationships in future studies. Interestingly, no evidence of mediation was apparent for the alcohol consumption subscale of the AUDIT. This seems to suggest that mediation may be more pertinent in predicting alcohol-related problems and dependence. Arguably, those who experience alcohol-related problems and signs of dependence may have developed drinking as a coping strategy and be more preoccupied with 
drinking. Investigation of these relationships in clinical samples is warranted to determine whether this proposition holds.

It is noteworthy that the current sample reported high levels of risky drinking behavior, and the majority reported alcohol-related problems. Of concern, over one-quarter of the sample endorsed items consistent with risk for alcohol dependence. It is important to note that the AUDIT is not a diagnostic tool, but was developed as a screening instrument to assist in determining when further intervention might be advisable (Babor \& Higgins-Biddle, 2001). However the observation that over $75 \%$ of the present sample reported alcohol-related problems suggests that greater efforts are needed to curb risky drinking behavior and associated consequences among young people. Further, although gender differences were evident, with men reporting greater consumption and dependence, no gender differences were noted in alcohol-related problems. This suggests that although drinking less, women are reaching similar levels of intoxication and experiencing similar consequences to men in this sample.

While educators, clinicians and policy makers are continually improving harm minimisation efforts, the present finding that the majority of the sample reported consuming their first drink under the age of 16, with one-quarter of the sample consuming their first drink before the age of 13 , suggests greater focus is required on prevention and early intervention initiatives with school-aged children. Although early experimentation with alcohol is not uncommon (AIHW, 2008), and does not necessarily indicate problem drinking at this early age, studies have repeatedly shown a relationship between age of drinking and later development of alcohol-use disorders (e.g. Grant, Stinson, \& Harford, 2001). A recent study revealed that adolescents who begin drinking at a younger age tend to have lower selfesteem, are less resistant to peer pressure, and are at greater risk of later alcohol 
abuse/dependence, antisocial personality symptoms and arrests (Flory, Lynam, Milich, Leukefeld, \& Clayton, 2004).

\section{Limitations}

The results of this study must be considered in light of the study's limitations. Naturally the correlational design precludes speculation about causal relationships between the variables, and longitudinal designs with a larger and more representative sample are warranted. The interpretation of the results must be considered tentative, as there are several variables which may lead to alternative explanations, or further clarify the nature of the observed relationships. Firstly, we did not assess the setting in which drinking typically occurs for the young people in our sample. Motives to drink, and the ability to restrain drinking, are likely to differ across different drinking contexts. Indeed it has often been noted that an individual's belief in their ability to resist drinking varies according to the situation (Oei, Hasking, \& Young, 2005; Oei, Hasking, Young, \& Loveday, 2007).

Secondly, although use of the AUDIT subscales allowed an examination of the differential relationships between drinking motives, drinking restraint, alcohol consumption and alcoholrelated problems, we did not differentiate between frequency and volume of alcohol consumed. Given the high rates of binge drinking often observed in young adult samples (AIHW, 2008; Kuntsche, et al., 2005; O’Hara, 1990; Wechsler \& Isaac, 1992), future research would benefit from consideration of how motives and restraint are differentially related to frequency of alcohol consumption, and volume of alcohol consumed in single drinking sessions. Finally, we did not assess psychological constructs that may be related to both drinking motives and alcohol consumption. For example, a coping motive implies that the individual is drinking in order to cope with either an internal or external stressor, whereas social and conformity motives imply a level of social interaction or a peer group with positive drinking attitudes. Assessment of psychological distress, external stressors, social support 
and peer norms in future research would aid in clarifying the relationships observed in the current study.

\section{Implications}

Despite the limitations noted above, the results of the current study suggest several avenues for prevention of and early intervention for risky alcohol consumption and alcoholrelated problems. The young age of initiation, and salience of social motives, reported by this sample suggests that greater focus on refusal skills should be incorporated into existing prevention programs. In addition, the strength of the association between enhancement motives and all criterion variables suggests that such programs may also benefit from further examination of ways in which young people can achieve a 'natural high'. Encouragement of alternate activities that are incompatible with drinking would likely result in a reduction of alcohol-related problems among young people and foster positive health attitudes.

As expected, coping motives were related to alcohol problems and signs of dependence. Although the causal direction of this relationship cannot be established within the current study, the results suggest that an additional focus on coping skills training may reduce drinking to cope among those at risk. However, the effects of coping motives were also mediated by CEP, suggesting that the preoccupation with drinking, rather than coping motives, are the more proximal predictor of drinking. Cognitive therapy, with a particular focus on recognising automatic thoughts and challenging urges to drink, may prove fruitful in those who use alcohol to cope. Such an approach is routinely utilised in treatment of alcohol dependence (Beck et al., 1993), however the current results suggest such strategies may also help limit drinking in non-clinical samples.

\section{Conclusion}

In summary, the current study has advanced the literature on correlates of drinking by establishing the salience of coping, enhancement and social motives when predicting drinking 
behavior among young people. Further, although the mediating role of drinking restraint in this relationship warrants further investigation, our results are encouraging, as they suggest that further examination of these relationships will yield useful implications for prevention and early intervention initiatives designed to reduce risky drinking and associated adverse consequences for young people. 


\section{References}

Australian Institute of Health and Welfare (AIHW) (2008). 2007 National Drug Strategy Household Survey. Canberra: Australian Government Publishing Service.

Babor T.F., \& Higgins-Biddle J.C. (2001). Brief Intervention for Hazardous and Harmful Drinking: A Manual for Use in Primary Care. Geneva, Switzerland: World Health Organization.

Baron, R.M., \& Kenny, D.A. (1986). The moderator-mediator variable distinction in social psychological research: Conceptual, strategic and statistical considerations. Journal of Personality \& Social Psychology, 51, 1173-1182.

Beck, A.T., Wright, F.D., Newman, C.F., \& Liese, B.S. (1993). Cognitive therapy of substance abuse. New York, NY: Guilford Press.

Bensley, L.S., Kuna, P.H., \& Steele, C.M. (1990). The role of drinking restraint success in subsequent alcohol consumption. Addictive Behaviors, 15, 491-496.

Bradizza, C.M., Reifman, A., \& Barnes, G.M. (1999). Social and coping reasons for drinking: Predicting alcohol misuse in adolescents. Journal of Studies on Alcohol, 60, 491-499.

Collins, R.L., George, W.H., Lapp, W.M. (1989). Drinking restraint: Refinement of a construct and prediction of alcohol consumption. Cognitive Therapy and Research, 13, 423-440.

Collins, R.L., Koutsky, J.R., Morsheimer, E.T., \& MacLean, M.G. (2001). Binge drinking among underage college students: A test of restraint-based conceptualisation of risk for alcohol abuse. Psychology of Addictive Behaviors, 15, 333-340.

Collins, R.L. \& Lapp, W.M. (1992). The Temptation and Restraint Inventory for measuring drinking restraint. British Journal of Addiction, 87, 625-633. 
Connor, J.P., Gudgeon, E.T., Young, R.McD., \& Saunders, J.B. (2004). The role of drinking restraint in alcohol dependence: Validation of the temptation and restraint inventory in an alcohol dependent sample. Journal of Studies on Alcohol, 65, 250-254.

Connors, G.J., Collins, L.R., Dermen, K.H., \& Koutsky, J.R. (1998). Substance use restraint: An extension of the construct to a clinical population. Cognitive Therapy and Research, $22,75-87$.

Cooper, M.L. (1994) Motivations for alcohol use among adolescents: Development and validation of a four-factor model. Psychological Assessment, 6, 117-128.

Cooper, M.L., Frone, M.R., Russell, M., \& Mudar, P. (1995). Drinking to regular positive and negative emotions: A motivational model of alcohol use. Journal of Personality and Social Psychology, 69, 990-1005.

Cooper, M.L., Russell, M., Skinner, J.B., \& Windle, M. (1992). Development and validation of a three-dimensional measure of drinking motives. Psychological Assessment, 4, 123 132.

Cox, W.M., Gutzler, M., Denzler, M., Melfsen, I.F., \& Klinger, E. (2001). Temptation, restriction, and alcohol consumption among American and German college students. Addictive Behaviors, 26, 573-581.

Cox, W.M., Hosier, S.G., Crossley, S., Kendall, B., \& Roberts, K.L. (2006). Motives for drinking, alcohol consumption, and alcohol-related problems among British secondaryschool and university students. Addictive Behaviors, 31, 2147-2157.

Cox, W.M., \& Klinger, E. (1988). A motivational model of alcohol use. Journal of Abnormal Psychology, 97, 168-180.

Flory, K., Lynam, D., Milich, R., Leukefeld, C., \& Clayton, R. (2004). Early adolescent through young adult alcohol and marijuana use trajectories: Early predictors, young adult outcomes and predictive utility. Development and Psychopathology, 16, 193-213. 
Grant, B. F., Stinson, F. S., \& Harford, T. C. (2001). Age at onset of alcohol use and DSM-IV alcohol abuse and dependence: A 12-year follow-up. Journal of Substance Abuse, 13, 493-504.

Grant, V.V., Stewart, S.H., O’Connor, R.M., Blackwell, E., \& Conrod, P.J. (2007). Psychometric evaluation of the five-factor modified drinking motives questionnaire revised in undergraduates. Addictive Behaviors, 32, 2611-2632.

Hingson, R.W., Heeren, T., Zakocs, R.C., Kopstein, A., \& Wechsler, H. (2002). Magnitude of alcohol-related mortality and morbidity among U.S. college students ages 18-24. Journal of Studies on Alcohol, 63, 136-144.

Kuntsche, E., Knibbe, R., Gmel, G., \& Engels., R. (2005). Why do young people drink? A review of drinking motives. Clinical Psychology Review, 25, 841-861.

MacKillop, J., Lisman, S.A., \& Weinstein, A. (2006). Psychometric validation of the temptation and restraint inventory in two samples of college drinkers. Journal of Psychopathology and Behavioral Assessment, 28, 157-163.

MacLean, M.G., \& Lecci, L. (2000). A comparison of models of drinking motives in a university sample. Psychology of Addictive Behaviors, 14, 83-87.

Martens, M.P., Ferrier, A.G., \& Cimini, M.D. (2007). Do protective behavioral strategies mediate the relationship between drinking motives and alcohol use in college students? Journal of Studies on Alcohol and Drugs, 68, 106-114.

McNally, A.M., Palfai, T.P., Levine, R.V., \& Moore, B.M. (2003). Attachment dimensions and drinking-related problems among young adults: The mediational role of coping motives. Addictive Behaviors, 28, 1115-1127.

Munro, G. (2000). Challenging the culture of sport and alcohol. International Journal of Drug Policy, 11, 199-202. 
Muraven, M., Collins, L.R., \& Nienhaus, K. (2002). Self-control and alcohol restraint: An initial application of the self-control strength model. Psychology of Addictive Behaviors, $16,113-120$.

Oei, T.P.S., Hasking, P.A., \& Young, RMcD. (2005). Drinking refusal self-efficacy questionnaire - revised (DRSEQ-R): A new factor structure with confirmatory factor analysis. Drug and Alcohol Dependence, 78, 297-307.

Oei, T.P.S., Hasking, P.A., Young, R.M., \& Loveday, W. (2007). Validation of the Drinking Refusal Self-Efficacy Questionnaire - Revised in an adolescent sample (DRSEQ-RA). Addictive Behaviors, 32, 862-868.

O’Hara, T.M. (1990). Dinking in college: Consumption patterns, problems, sex differences and legal drinking age. Journal of Studies on Alcohol, 51, 536-541.

Perkins, W.H. (2002). Surveying the damage: A review of research on consequences of alcohol misuse in college populations. Journal of Studies on Alcohol, 14, 91-100.

Read, J.P., Wood, M.D., Kahler, C.W., Maddock, J.E., \& Palfai, T.P. (2003). Examining the role of drinking motives in college student alcohol use and problems. Psychology of Addictive Behaviors, 17, 13-23.

Reinert, D.F., \& Allen, J.P. (2007). The alcohol use disorders identification test: An update of research findings. Alcoholism: Clinical and Experimental Research, 31, 185-199.

Roche, A.M. \& Watt, K. (1999). Drinking and university students: From celebration to inebriation. Drug and Alcohol Review, 18, 389-399.

Stewart, S.H., \& Chambers, L. (2000). Relationships between drinking motives and drinking restraint. Addictive Behaviors, 25, 269-274.

Stewart, S.H., Zeitlin, S.B., \& Samoluk, S.B. (1996). Examination of a three-dimensional drinking motives questionnaire in a young adult university student sample. Behavioral Research Therapy, 34, 61-71. 
Wechsler, H. \& Isaac, N. (1992). 'Binge' drinkers at Massachusetts colleges. Journal of the American Medical Association, 267, 2929-2932.

Williams, R.J., \& Ricciardelli, L.A. (1999). Restrained drinking and cognitive control among adolescents. Adolescence, 34, 557-565. 
Table 1.

Percentage of sample reporting low risk versus risky drinking as defined by AUDIT total scores and subscale scores.

\begin{tabular}{|l|c|c|c|c|}
\hline & Total AUDIT & Alcohol & Alcohol-related & Dependence \\
& & ponsumption & problems & \\
\hline Low risk & 31.4 & 46.3 & 22.2 & 73.5 \\
\hline Risky drinking & 68.6 & 53.7 & 77.8 & 26.5 \\
\hline
\end{tabular}


Table 2.

Descriptive statistics and correlations between variables.

\begin{tabular}{|c|c|c|c|c|c|c|c|c|c|c|}
\hline & Mean (sd) & 2 & 3 & 4 & 5 & 6 & 7 & 8 & 9 & 10 \\
\hline 1. AUDIT total & $12.33(7.50)$ & $.85 * * *$ & $.90 * * *$ & $.84 * * *$ & $.38 * * *$ & $.60 * * *$ & $.14^{*}$ & $.55 * * *$ & $.64 * * *$ & $.31 * * *$ \\
\hline 2. Consumption & $6.56(2.75)$ & - & $.61 * * *$ & $.62 * * *$ & $.27 * * *$ & $.61 * * *$ & .06 & $.58 * * *$ & $.51 * * *$ & $.16^{*}$ \\
\hline 3. Alcohol problems & $3.81(3.56)$ & & - & $.64 * * *$ & $.36 * * *$ & $.46^{* * *}$ & $.15^{*}$ & $.43 * * *$ & $.56 * * *$ & $.39 * * *$ \\
\hline 4. Dependence & $2.23(2.23)$ & & & - & $.35 * * *$ & $.47 * * *$ & .11 & $.37 * * *$ & $.60 * * *$ & $.25 * * *$ \\
\hline 5. Coping motives & $2.35(1.12)$ & & & & - & $.50 * * *$ & $.38 * * *$ & $.33 * * *$ & $.61 * * *$ & $.24 * * *$ \\
\hline 6. Enhancement motives & $3.74(1.33)$ & & & & & - & $.24 * * *$ & $.66 * * *$ & $.56 * * *$ & $.19 * *$ \\
\hline 7. Conformity motives & $1.81(.80)$ & & & & & & - & $.33 * * *$ & $.31 * * *$ & $.21 * *$ \\
\hline 8. Social motives & $3.97(1.22)$ & & & & & & & - & $.46^{* * *}$ & $.16^{* *}$ \\
\hline 9. $\mathrm{CEP}^{\mathrm{a}}$ & $2.75(1.47)$ & & & & & & & & - & $.48 * * *$ \\
\hline 10. $\mathrm{CBC}^{\mathrm{b}}$ & $2.80(1.54)$ & & & & & & & & & - \\
\hline
\end{tabular}

${ }^{\mathrm{a}}$ Cognitive and Emotional Preoccupation ${ }^{\mathrm{b}}$ Cognitive and Behavioral Control 
Table 3.

Regression analyses predicting total AUDIT scores

\begin{tabular}{|c|c|c|c|c|c|c|c|}
\hline & B & $\beta$ & $\mathrm{R}$ & $\mathrm{R}^{2}$ & $\Delta \mathrm{R}^{2}$ & df & $\mathrm{F}$ \\
\hline Step 1 & & & .28 & .08 & .08 & 2,218 & $9.04 * * *$ \\
\hline Age & -.27 & -.11 & & & & & \\
\hline Gender & -4.37 & $-.27 * * *$ & & & & & \\
\hline Step 2 & & & .68 & .46 & .39 & 4,214 & $38.71 * * *$ \\
\hline Coping motives & .93 & $.14^{*}$ & & & & & \\
\hline Social motives & 1.71 & $.28 * * *$ & & & & & \\
\hline Conformity motives & -1.00 & -.11 & & & & & \\
\hline Enhancement motives & 2.03 & $.36 * * *$ & & & & & \\
\hline Step 3 & & & .74 & .55 & .09 & 2,212 & $21.03 * * *$ \\
\hline CEP & 2.02 & $.40 * * *$ & & & & & \\
\hline $\mathrm{CBC}$ & .24 & .05 & & & & & \\
\hline
\end{tabular}


Table 4.

Regression analyses predicting AUDIT subscales

\begin{tabular}{|c|c|c|c|c|c|c|c|c|c|c|c|c|c|c|c|c|c|c|c|}
\hline & \multicolumn{7}{|c|}{ Alcohol dependence } & \multicolumn{4}{|c|}{ Alcohol-related problems } & \multicolumn{8}{|c|}{ Alcohol consumption } \\
\hline & $\mathrm{B}$ & $\beta$ & $\mathrm{R}$ & $\mathrm{R}^{2}$ & $\Delta \mathrm{R}^{2}$ & $\mathrm{~F}$ & B & $\beta$ & $\mathrm{R}$ & $\mathrm{R}^{2}$ & $\Delta \mathrm{R}^{2}$ & $\mathrm{~F}$ & $\mathrm{~B}$ & $\beta$ & $\mathrm{R}$ & $\mathrm{R}^{2}$ & $\Delta \mathrm{R}^{2}$ & $\mathrm{~F}$ & df \\
\hline Step 1 & & & .24 & .06 & .06 & $6.41 * *$ & & & .16 & .02 & .02 & .02 & & & .30 & .09 & .09 & $10.85 \dagger$ & 2,218 \\
\hline Age & -.06 & -.09 & & & & & -.12 & -.11 & & & & & -.07 & -.08 & & & & & \\
\hline Gender & -1.10 & $-.23 * *$ & & & & & -.98 & -.13 & & & & & -1.78 & $-.30 \dagger$ & & & & & \\
\hline Coping motives & .33 & $.17^{*}$ & & & & & .57 & $.18^{*}$ & & & & & .00 & .00 & & & & & \\
\hline Social motives & .15 & .08 & & & & & .58 & $.20^{*}$ & & & & & .67 & $.30 \dagger$ & & & & & \\
\hline Conform. motives & -.20 & -.07 & & & & & -.23 & -.05 & & & & & -.51 & $-.15^{* *}$ & & & & & \\
\hline Enhance. motives & .51 & $.31 \dagger$ & & & & & .58 & $.22 *$ & & & & & .82 & $.41 \dagger$ & & & & & \\
\hline Step 3 & & & .61 & .37 & .11 & $18.74 \dagger$ & & & .61 & .37 & .12 & $20.88 \dagger$ & & & .70 & .50 & .03 & $6.36^{* *}$ & 2,212 \\
\hline CEP & .73 & $.49 \dagger$ & & & & & .83 & $.35 \dagger$ & & & & & .50 & $.27 * *$ & & & & & \\
\hline $\mathrm{CBC}$ & -.04 & -.03 & & & & & .40 & $.18^{* *}$ & & & & & -.08 & -.05 & & & & & \\
\hline
\end{tabular}




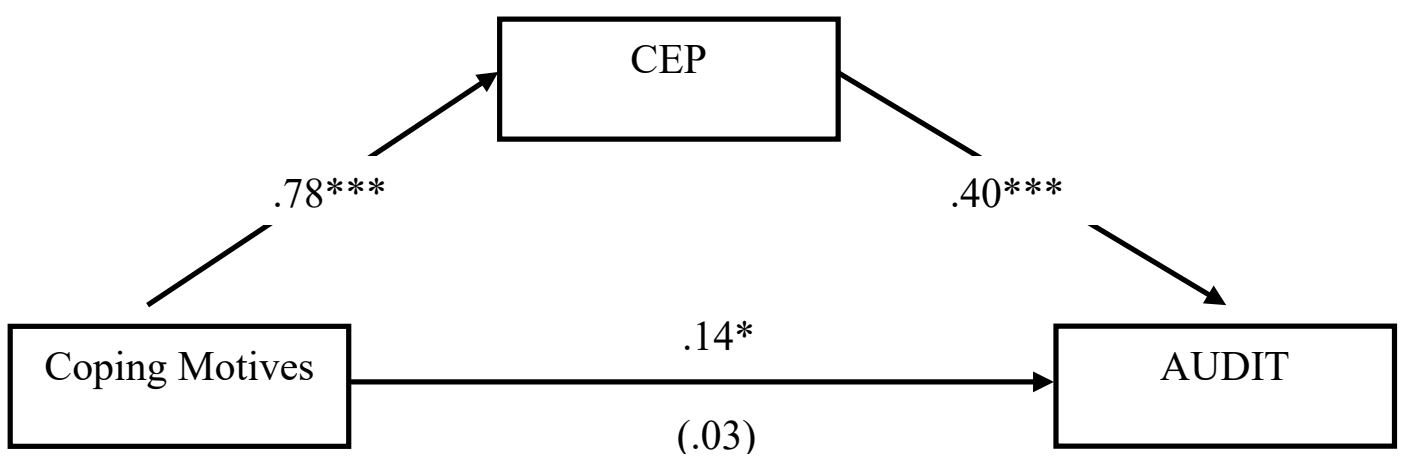

Figure 1.

CEP mediates the relationship between coping motives and AUDIT total score. 